\title{
Morfologia das plântulas, anatomia e venação dos cotilédones e eofilos de três espécies de Mimosa (Fabaceae, Mimosoideae)
}

Seedling morphology, anatomy and venation of the cotyledons and eophylls of Mimosa (Fabaceae, Mimosoideae)

\author{
Jonathas Henrique Georg de Oliveira ${ }^{1,4}$, Maísa Carvalho Iwazaki ${ }^{2}$ \& Denise Maria Trombert Oliveira ${ }^{3}$
}

\begin{abstract}
Resumo
A fase pós-seminal é uma das mais críticas do ciclo de vida dos vegetais, responsável pelo estabelecimento do indivíduo. Mimosa é um gênero amplo, com espécies utilizadas para recuperação de áreas degradadas; o conhecimento de fases juvenis é indispensável para a identificação no campo. Este trabalho compara a morfologia das plântulas, a anatomia e a venação dos cotilédones e eofilos de Mimosa daleoides, M. dolens var. anisitsii e $M$. orthacantha, adotando métodos usuais em morfologia e microscopia de luz. A germinação ocorre entre um e três dias. São plântulas fanero-epígeo-foliáceas, com expansão dos cotilédones entre dois a cinco dias após a germinação; cotilédones semelhantes, actinódromos e anfiestomáticos. A filotaxia dos cotilédones é oposta e dos eofilos é alterna. O número de pares de folíolos no primeiro eofilo varia de dois a três em M. daleoides e M. dolens var. anisitsii e de cinco a sete em $M$. orthacantha. O limbo foliolar apresenta anatomia semelhante entre as espécies, é anfiestomático, dorsiventral, com uma camada de parênquima paliçádico bem desenvolvida; a epiderme de M. dolens var. anisitsii apresenta idioblastos fenólicos e apêndices lignificados no bordo foliolar. O padrão de venação é broquidódromo, com algumas variações em M. orthacantha. Os resultados obtidos permitem a identificação de espécies de Mimosa em sua fase juvenil, fornecendo dados que podem apoiar estudos taxonômicos e ecológicos com o gênero.
\end{abstract}

Palavras-chave: desenvolvimento pós-seminal, eofilo, heterofilia juvenil, venação.

\begin{abstract}
The post-seminal phase is the most critical on life cycle of plants, responsible for establishing a new individual. Mimosa is a large genus comprising species used for recovery of degraded areas; the knowledge of their juvenile stages is essential for their identification. This article describes and compares the seedling morphology, anatomy and venation of the cotyledons and eophylls of Mimosa daleoides, $M$. dolens var. anisitsii and $M$. orthacantha, adopting usual methods in morphology and light microscopy. The germination occurs between one and three days. Seedlings are phanero-epigeal-foliaceous, with expansion of cotyledons between two to five days after germination; cotyledons are similar, actinodromous and amphistomatic. The phyllotaxy of the cotyledons is opposite and of the eophylls is alternate. The number of leaflet pairs in the first eophyll ranges from two to three in M. dolens and M. daleoides var. anisitsii and from five to seven in $M$. orthacantha. The leaflet blade is anatomically similar between the species: amphistomatic, dorsiventral, with a well-developed layer of palisade parenchyma. Phenolic idioblasts are present throughout the epidermis of $M$. dolens var. anisitsii, which also displays lignified appendices in the leaflet edge. The venation pattern is brochidodromous, with some variations in $M$. orthacantha. The results allow the identification of Mimosa species in their juvenile stage, providing data that can support taxonomic and ecological studies of the genus. Key words: eophyll, post-seminal development, juvenile heterophylly, venation.
\end{abstract}

\section{Introdução}

A anatomia foliar das plântulas é pouco conhecida quando comparada à de órgãos vegetativos adultos; no entanto, estudos anatômicos desta fase da vida do vegetal, em complementação aos estudos de morfologia externa, mais comuns, podem revelar muito a respeito da história evolutiva, ecológica (Duke \& Polhill 1981) e filogenética da espécie, visto que as plântulas podem reter estados de caracteres, derivados ou não, muitas vezes efêmeros (Ricardi

\footnotetext{
${ }^{1}$ Universidade Estadual de Maringá, Depto. Biologia, Av. Colombo 5790, bl. G80, s/113, 87020-900, Maringá, PR, Brasil.

${ }^{2}$ UNESP - Universidade Estadual Paulista, Depto. Botânica, Programa de Pós-graduação em Ciências Biológicas, C.P. 510, 18618-000 Botucatu, SP, Brasil.

${ }^{3}$ Universidade Federal de Minas Gerais, Inst. Ciências Biológicas, Depto. Botânica, Av. Antônio Carlos 6627, C.P. 486, 31270-901, Belo Horizonte, MG, Brasil.

${ }^{4}$ Autor para correspondência: jonathas229@yahoo.com.br
} 
1996). O conhecimento da estrutura das plântulas, por exemplo, pode auxiliar na identificação precoce, colaborando para a seleção de espécies úteis e/ou favorecendo o controle de invasoras (Duke \& Polhill 1981). Essa fase compreende um período crítico no ciclo de vida dos vegetais e pouco se conhece a esse respeito (Duke \& Polhill 1981; Oliveira 2001).

Descrições morfológicas de plântulas de Fabaceae (=Leguminosae), segunda maior família de Angiospermas em importância econômica (Judd et al. 2009), são mais comuns que na maioria dos grupos. Entretanto, para Mimosa L., registram-se poucas iniciativas, como os trabalhos de Parra (1984), que descreveu a morfologia externa de plântulas de quatro espécies, dentre elas $M$. albida Humb. \& Bompl. ex Willd., M. arenosa Poir., M. camporum Benth. e M. tenuiflora Benth.; Camargo-Ricalde \& Grether (1998), que descreveram a germinação e a plântula de M. tenuiflora, destacando a grande produção de sementes de pequeno porte, que podem favorecer sua invasão em áreas abertas; e Oliveira (1999), que caracterizou a plântula de $M$. caesalpiniaefolia Benth., verificando que o desenvolvimento pósseminal é rápido e o primeiro eofilo expande-se 12 dias após a semeadura.

Com relação aos cotilédones de Fabaceae, merecem destaque os trabalhos de Smith (1981, 1983), Smith \& Scott $(1985,1995)$ e Scott \& Smith (1998), os quais avaliaram a anatomia, incluindo venação, reservas e formas de mobilização cotiledonares. Para esses autores, tais informações podem fornecer importantes subsídios, com implicações taxonômicas, ecológicas e filogenéticas.

Uma comparação entre os cotilédones e os eofilos de Faboideae (= Papilionoideae) foi feita por Saint-Martin (1984), que abordou várias características estruturais e propôs, ao final, uma hipótese filogenética para o grupo. Mais recentemente, Moreira-Coneglian \& Oliveira (2006), trabalhando com espécies de Caesalpinioideae, estudaram os limbos cotiledonares e eofilares e confirmaram que a complexidade estrutural é maior nos eofilos; as autoras sugeriram novos estudos com Fabaceae, para que seja possível utilizar essas informações para verificar relações taxonômicas e filogenéticas. Oliveira (1999) também frisou esse aspecto, especialmente destacando a necessidade de se estudarem espécies de ambientes mais específicos, como feito por Ressel et al. (2004), que analisaram as plântulas de três formações, comparando o tipo de desenvolvimento com grupos sucessionais.
De outro ponto de vista, Garwood (1996) descreveu a morfologia das plântulas de várias famílias com enfoque funcional, comparando os tipos de plântulas e suas possíveis funções, distribuições e relações com o ambiente onde se reproduzem, chegando aos seguintes tipos morfofuncionais: fanero-epígeo-foliácea (PEF), fanero-epígeo-armazenador (PER), fanero-hipógeoarmazenador (PHR), cripto-hipógeo-armazenador (CHR) e cripto-epígeo-armazenador (CER).

Para o presente trabalho, foram selecionadas três espécies: M. daleoides Benth., M. dolens Vell. var. anisitsii (Lindm.) Barneby e M. orthacantha Benth., ocorrentes em áreas remanescentes de cerrado do estado de São Paulo. Este estudo visou a descrever a morfologia das plântulas das três espécies, até a expansão do primeiro eofilo, e comparar a anatomia, em especial o padrão de venação, dos cotilédones e do primeiro eofilo, fornecendo dados para subsidiar a sistemática do grupo e contribuir com as identificações em campo, uma vez que isso se mostra difícil, devido à falta de literatura para referência.

\section{Material e Métodos}

Os vouchers das espécies encontram-se depositados no Herbário "Irina D. Gemtchujnicov" (BOTU), do Departamento de Botânica da UNESP (Botucatu), sob os registros: Mimosa daleoides Benth. (20.556), M. dolens Vell. var. anisitsii (Lindm.) Barneby (19.497) e M. orthacantha Benth. (19.374).

As sementes de $M$. daleoides e $M$. orthacantha foram coletadas às margens da rodovia Gastão dal Farra, km 5-7 (22 $26^{\prime}$ 'S; $\left.48^{\circ} 26^{\prime} \mathrm{W}\right)$ e de $M$. dolens var. anisitsii às margens da ferrovia, no distrito de Rubião Junior (22 $53^{\prime}$ 'S; $48^{\circ} 29^{\prime} \mathrm{W}$ ), todas no município de Botucatu, São Paulo, Brasil.

A produção de plântulas foi realizada a partir de amostras de 50 sementes aleatórias dos 5 indivíduos selecionados de cada espécie, escarificadas mecanicamente com lixa d'água (Ferreira \& Borghetti 2004), forma mais eficiente e prática neste caso. Foram semeadas em caixa de isopor, próprias para produção de mudas, contendo mistura de solo do local de coleta e areia (1:1) e mantidas sob sombrite de $50 \%$. As plântulas foram regadas e observadas diariamente até a completa expansão do primeiro eofilo. Considerou-se semente germinada a que apresentava a protrusão da raiz primária.

Para a descrição morfológica, foram coletadas plântulas em vários estádios de desenvolvimento, até 
a expansão do primeiro eofilo. Para análise anatômica, foram utilizados pecíolo e limbo cotiledonar, além de ráquis e folíolos do primeiro eofilo.

Os limbos foram descritos adotando-se a nomenclatura proposta por Hickey (1979).

O material destinado para confecção de laminário permanente foi fixado em FAA 50 (Johansen 1940) e conservado em etanol 70\% (Jensen 1962). Seguiu-se a desidratação em série etílica e inclusão em metacrilato (Leica ${ }^{\circledR}$ ), segundo o protocolo do fabricante. O material foi seccionado em micrótomo de rotação (Leica RM2235) com 8 a $10 \mu \mathrm{m}$ de espessura, corado com azul de toluidina 0,05\% em pH 4,7 (O'Brien et al. 1964, modificado) e montado em resina sintética. Lâminas semipermanentes foram elaboradas a partir de material recém-coletado, seccionado a mão livre com lâmina de aço descartável, corado com safranina e azul de astra (Kraus \& Arduin 1997) e montado em gelatina glicerinada.

Análises das epidermes cotiledonares e eofilares foram realizadas utilizando-se impressões das lâminas foliares feitas com cola Super-Bonder ${ }^{\circledR}$.

Para a análise do padrão de venação, o cotilédone e o primeiro eofilo de cada espécie foram diafanizados pela técnica de Fuchs (1963) e montados em gelatina glicerinada. A descrição da venação foi baseada nos trabalhos de Hickey (1979) e Smith \& Scott (1995). A descrição morfológica das plântulas seguiu a nomenclatura de tipos morfofuncionais (com siglas mantidas em inglês, para facilitar comparações), conforme sugerido por Garwood (1996).

Testes histoquímicos foram feitos com os seguintes reagentes/corantes: floroglucinol em meio ácido, cloreto férrico, lugol, Sudan IV (Johansen 1940) e vermelho de rutênio (Jensen 1962), para a detecção, respectivamente, de lignina, compostos fenólicos, amido, lipídios e substâncias pécticas. Os resultados foram analisados em microscópio estereoscópico (Leica ${ }^{\circledR}$ EZ4D) e microscópio de luz (Leica ${ }^{\circledR}$ ICC50). Os desenhos foram feitos em câmara clara e as fotografias produzidas em fotomicroscópio Zeiss ${ }^{\circledR}$, modelo Wild M20, compondo as escalas nas condições ópticas utilizadas.

\section{Resultados}

Morfologia das plântulas

As sementes das três espécies apresentam tegumento impermeável, resistente e de consistência córnea, fazendo-se necessária a escarificação de maneira a quebrar a barreira tegumentar. Após escarificação, o tempo de protrusão da raiz primária (Fig. 1a-c) em Mimosa daleoides é de três dias e, para as outras espécies, entre um e dois dias.

A raiz primária pode ou não se ramificar até a expansão do primeiro eofilo e se alonga bastante, porém nódulos radiculares não foram observados até o final da fase estudada. O colo é evidente e o hipocótilo das três espécies é arroxeado e de aspecto glabro. Contudo, tricomas esparsos podem ser observados em $M$. daleoides e $M$. orthacantha.
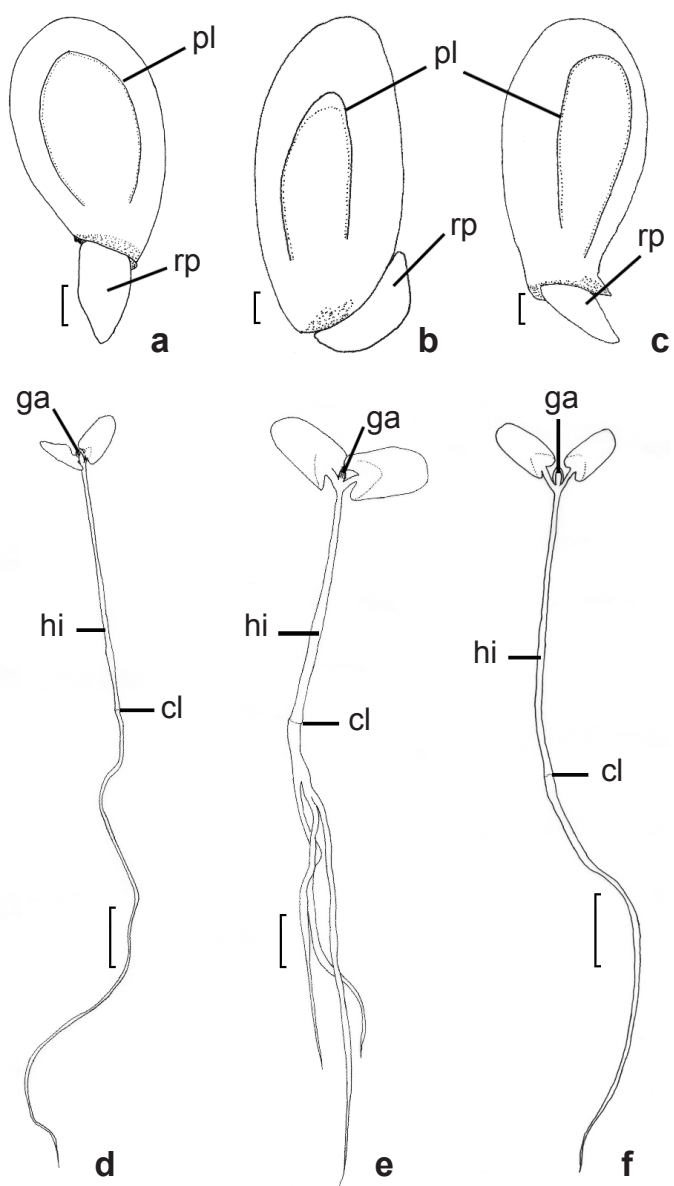

Figura 1 - Morfologia das plântulas de Mimosa daleoides (a, d), Mimosa dolens var. anisitsii (b, e) e Mimosa orthacantha (c, f) - a-c. protrusão da raiz primária; d-f. plântulas com cotilédones expandidos. (cl: coleto, ga: gema apical, hi: hipocótilo, pl: pleurograma, rp: raiz primária). Barras: 2,5 mm (a-c), $5 \mathrm{~mm}$ (d-f).

Figure 1 - Seedling morphology of Mimosa daleoides (a, d), Mimosa dolens var. anisitsii (b, e) and Mimosa orthacantha. (c, f) - a-c. primary root protrusion; $d-f$. seedlings with expanded cotyledons. (cl: root-shoot transition, ga: apical meristem, hi: hypocotyl, pl: pleurogram, rp: primary root). Bars: $2.5 \mathrm{~mm}$ (a-c), $5 \mathrm{~mm}(\mathrm{~d}-\mathrm{f})$. 
Os cotilédones das espécies analisadas apresentam filotaxia oposta, sendo que o primeiro eofilo mostra-se alterno.

A expansão total dos cotilédones ocorre quatro dias após a germinação em $M$. daleoides, cinco dias em $M$. dolens var. anisitsii e em apenas dois dias em $M$. orthacantha. Caracterizam-se como verdes, foliáceos, peciolados e pulvinulados, demonstrando movimentos nictinásticos, ou seja, alterando a posição da folha entre o dia e a noite.

Para M. daleoides, os cotilédones são largoovados, glabros, curto-peciolados, com pecíolo de base arroxeada e ápice verde claro, limbo plano, verde escuro, com base levemente truncada e ápice obtuso (Fig. 1d). Em M. dolens var. anisitsii são ovados, muito largos, glabros, com pecíolo de coloração verde, lâmina cotiledonar glabra, verde, de base sagitada e ápice obtuso (Fig. 1e). Mimosa orthacantha exibe cotilédones estreito-ovados, pecíolo piloso e arroxeado, limbo verde, como na espécie anterior e glabro (Fig. 1f). Todas as espécies apresentam margem inteira e, em $M$. dolens var. anisitsii $\mathrm{e}$ M. orthacantha, a face adaxial mostra-se convexa. Um par de estípulas filiformes acompanha cada cotilédone.

Dez dias após a germinação, visualiza-se a expansão do primeiro eofilo em $M$. daleoides (Fig. 2a). Para as outras espécies o tempo é mais restrito ainda, oito dias para $M$. dolens var. anisitsii (Fig. 2b) e seis para M. orthacantha (Fig. 2c). São folhas compostas, paripinadas, longo-pecioladas, divergindo no número de folíolos entre as espécies: M. daleoides (Fig. 2d) e M. dolens var. anisitsii (Fig. 2e) exibem geralmente dois pares e $M$. orthacantha (Fig. 2f) varia de cinco a sete pares de folíolos. As três espécies exibem movimentos nictinásticos e seismonásticos (sensíveis ao toque), contudo, a seismonastia é mais rápida e evidente em
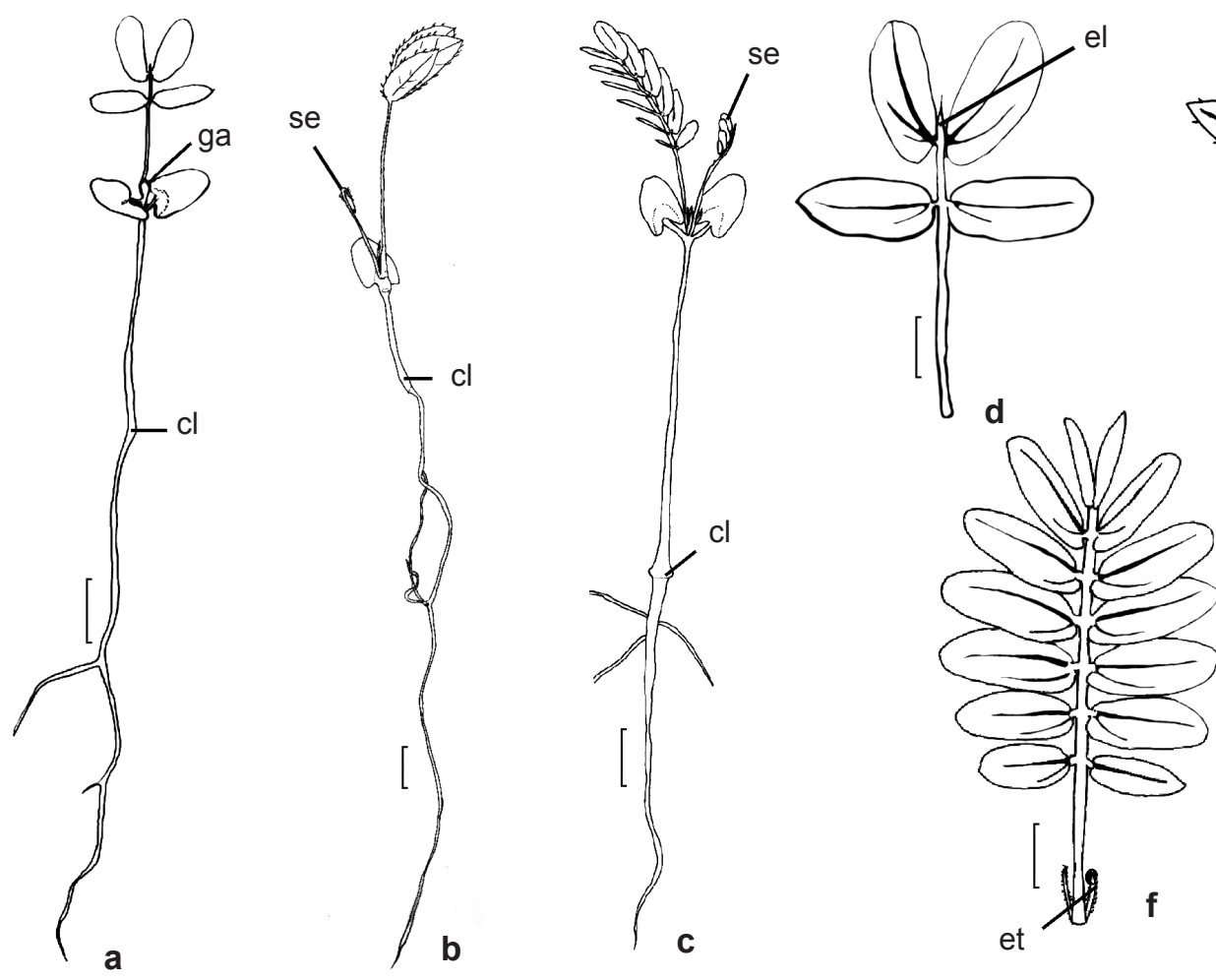

Figura 2 - Morfologia das plântulas de Mimosa daleoides (a, d), Mimosa dolens var. anisitsii (b, e) e Mimosa orthacantha (c, f) - a-c. plântulas com primeiro eofilo expandido; d-f. detalhes do primeiro eofilo. (cl: coleto, el: estipela, et: estípula, ga: gema apical, se: segundo eofilo). Barras: $5 \mathrm{~mm}$ (a-c), $3 \mathrm{~mm}$ (d-f).

Figure 2 - Seedling morphology of Mimosa daleoides (a, d), Mimosa dolens var. anisitsii (b, e) and Mimosa orthacantha (c, f) - a-c. seedlings with expanded first eophyll; d-f. details of the first eophyll. (cl: root-shoot transition, el: stipel, et: stipule, ga: apical meristem, se: second eophyll). Bars: $5 \mathrm{~mm}(\mathrm{a}-\mathrm{c}), 3 \mathrm{~mm}$ (d-f). 
M. orthacantha. Esses movimentos são realizados por pulvinos na base foliar e pulvínulos na base foliolar. Nas três espécies, a ráquis apresenta um prolongamento de aspecto foliáceo, constituindo uma estipela distal laminar. Um par de estípulas filiformes encontra-se presente na base do primeiro eofilo de cada espécie, sendo mais alongadas e levemente laminares em $M$. dolens var. anisitsii, inclusive com apêndices partindo do bordo.

Mimosa daleoides e M. orthacantha apresentam o primeiro eofilo com folíolos oblongos, de peciólulo reduzido, limbo de base assimétrica, mais acentuada no par de folíolos apical de $M$. orthacantha, ápice agudo e margem inteira. Mimosa daleoides mostra pecíolo, folíolos e ráquis pilosos, enquanto que em $M$. orthacantha, os tricomas ocorrem apenas no pecíolo. Mimosa dolens var. anisitsii tem pecíolo e folíolos glabros, limbos oblongos, de base assimétrica, ápice agudo e margem inteira; o par de folíolos apical tem assimetria basal mais evidente, além de pequenos apêndices agudos e voltados para o ápice, partindo do bordo do limbo.

\section{Anatomia do cotilédone}

Os pecíolos cotiledonares apresentam epiderme unisseriada, com células de paredes primárias levemente espessadas por substâncias pécticas e revestidas por fina cutícula. Em Mimosa dolens var. anisitsii, a epiderme do pecíolo cotiledonar apresenta células levemente papilosas e não apresenta tricomas. Nas duas outras espécies tricomas unicelulares são observados. $\mathrm{O}$ córtex parenquimático apresenta espaços intercelulares e a vascularização na base do pecíolo é feita por dois feixes vasculares colaterais justapostos (Fig. 3a).

Os limbos cotiledonares são anfiestomáticos e apresentam epiderme unisseriada, cuticulada e
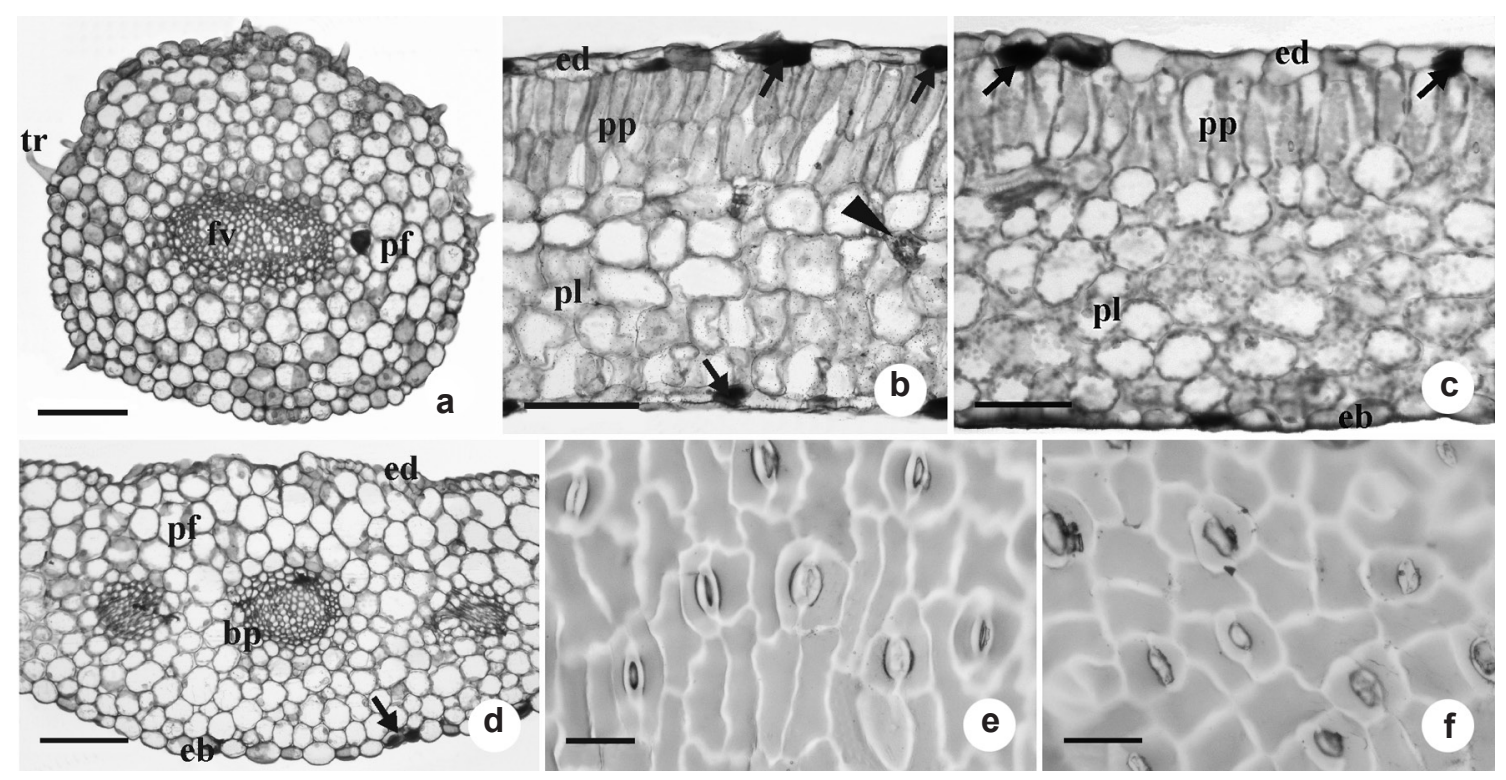

Figura 3 - Anatomia dos cotilédones de Mimosa daleoides (b, e), Mimosa dolens var. anisitsii (d) e Mimosa orthacantha (a, c, f). Secções transversais (a-d), impressões epidérmicas (e-f) - a. pecíolo; notar tricomas unicelulares; b-c. base do limbo cotiledonar, respectivamente com duas e uma camada de células paliçádicas (seta: idioblasto mucilaginoso, ponta de seta: cristal); d. aspecto do limbo na região da nervura central, envolta por bainha parenquimática (seta: idioblasto mucilaginoso); e-f. face abaxial e adaxial respectivamente; notar complexos estomáticos paracíticos. (bp: bainha parenquimática, eb: epiderme na face abaxial, ed: epiderme na face adaxial, fv: feixe vascular, pf: parênquima fundamental, pl: parênquima lacunoso, pp: parênquima paliçádico, tr: tricoma). Barras: $100 \mu \mathrm{m}$ (a-b), $75 \mu \mathrm{m}$ (c), $150 \mu \mathrm{m}$ (d), $25 \mu \mathrm{m}$ (e-f).

Figure 3 - Cotyledon anatomy of Mimosa daleoides (b, e), Mimosa dolens var. anisitsii (d) and Mimosa orthacantha (a, c, f). Cross sections (a-d), epidermal printings (e-f) - a. petiole; note unicellular trichomes; b-c. base of the cotyledonar lamina, with two and one layer of palisade cells, respectively (arrow: mucilaginous idioblast, arrowhead: crystal); d. aspect of lamina in vascular bundle region, surrounded by a parenchyma sheath (arrow: mucilaginous idioblast); e-f. abaxial and adaxial sides, respectively; note paracytic stomatal complexes. (bp: parenchyma sheath, eb: epidermis in the abaxial face, ed: epidermis in adaxial face, fv: vascular bundle, pf ground parenchyma, pl: spongy parenchyma, pp: palisade parenchyma, tr: trichome). Bars: $100 \mu \mathrm{m}$ (a-b), $75 \mu \mathrm{m}$ (c), $150 \mu \mathrm{m}$ (d), $25 \mu \mathrm{m}$ (e-f). 
glabra (Figs. 3b-d). Tanto na face abaxial quanto na adaxial, os estômatos mostram-se paracíticos (Figs. 3e-f). As faces anticlinais são levemente sinuosas em $M$. daleoides e $M$. dolens var. anisitsii, e as células são mais alongadas tangencialmente na face abaxial em M. daleoides (Fig. 3e) e poliédricas em ambas as faces de M. orthacantha (Fig. 3f). São evidenciados idioblastos mucilaginosos, dispostos na epiderme em ambas as faces para as três espécies (Fig. 3b-d). O mesofilo é dorsiventral e apresenta algumas diferenças estruturais entre as espécies. Apenas $M$. daleoides apresenta duas camadas de parênquima paliçádico voltadas para a face adaxial ao longo de todo o cotilédone (Fig. $3 b$ ); as outras duas espécies exibem a região basal do limbo com apenas uma camada de parênquima paliçádico (Fig. 3c) e, do meio do limbo em direção ao ápice, duas camadas. Cristais do tipo drusa são evidenciados no mesofilo de $M$. daleoides (Fig. 3b) e M. orthacantha. Na região da nervura central, verifica-se um amplo parênquima (Fig. $3 \mathrm{~d}$ ), exibindo três feixes vasculares colaterais na base do limbo. Em M. dolens var. anisitsii, o feixe central é de maior calibre que os dois laterais, os quais vão diminuindo de espessura conforme se afastam do pecíolo (Fig. 3d). A endoderme (bainha parenquimática) é observada no feixe central para as três espécies.

Com relação à vascularização, as três espécies apresentam cotilédones actinódromos (Fig. 4a-c), com três nervuras primárias partindo da base do limbo. Essas nervuras se ramificam de dois feixes, que se bifurcam na porção basal do pecíolo; os dois feixes centrais unem-se formando a nervura principal, que é curva em $M$. daleoides (Fig. 4a) e reta nas demais (Fig. 4b-c). As duas nervuras principais laterais se ramificam logo na base da folha, não alcançando sua margem, assim como todas as outras nervuras, inclusive de ordens superiores. O ângulo de divergência entre a nervura central e as duas laterais é agudo estreito, enquanto o ângulo das nervuras secundárias em relação às primárias é aproximadamente reto. Em M. dolens var. anisitsii e $M$. orthacantha as nervuras se ligam, próximas à margem, em série de arcos (Figs. 4b-c), o que não é verificado em M. daleoides (Fig. 4a). Nesta última espécie, as aréolas estão ausentes e as vênulas são simples ou ramificadas (Fig. 4d). Em M. dolens var. anisitsii e $M$. orthacantha, as aréolas são imperfeitas, com arranjo aleatório, poliédricas e também com vênulas simples ou ramificadas (Figs. 4e-f).
Raras traqueídes terminais são observadas nas três espécies.

\section{Anatomia do eofilo}

O pecíolo do eofilo apresenta epiderme unisseriada e varia entre as espécies quanto aos espessamentos parietais péctico-celulósicos e à presença de substâncias fenólicas. Em Mimosa dolens var. anisitsii, os espessamentos foram observados nas faces periclinais e anticlinais, além de acúmulo de substâncias fenólicas nos vacúolos das células epidérmicas (Fig. 5a); nas outras espécies, apenas as faces periclinais externas encontram-se espessadas (Fig. 5b), não evidenciando compostos vacuolares de natureza fenólica. Tricomas tectores unicelulares foram visualizados na epiderme de $M$. daleoides e $M$. orthacantha (Fig. 5b).

O córtex é parenquimático e clorofiliano, formado por apenas duas camadas de células. Poucos idioblastos cristalíferos estão presentes em M. dolens var. anisitsii (Fig. 5a), os quais ocorrem na endoderme (bainha) dos feixes vasculares em $M$. orthacantha. A vascularização é feita por um feixe bicolateral central e dois traços para os folíolos localizados lateralmente. $\mathrm{O}$ feixe exibe procâmbio e bainha esclerenquimática em $M$. daleoides e $M$. orthacantha; células esclerenquimáticas são observadas em $M$. dolens var. anisitsii, não constituindo bainha completa (Fig. 5a). Células secretoras são observadas apenas junto ao floema voltado para a face adaxial. Os traços foliolares são colaterais, com células esclerenquimáticas voltadas para a face floemática; em M. orthacantha, visualiza-se uma bainha cristalífera.

As lâminas de todos os folíolos do eofilo apresentam estrutura semelhante. A epiderme em ambas as faces é unisseriada, estomatífera, glabra e com células mucilaginosas (Figs. 5ce). Os estômatos são paracíticos e as paredes anticlinais variam de bem sinuosas em ambas as faces de $M$. daleoides (Fig. 5f) e na face abaxial de $M$. orthacantha, a levemente sinuosas em $M$. dolens var. anisitsii e na face adaxial de $M$. orthacantha (Fig. 5g). No bordo, principalmente do par de folíolos apical, estão presentes apêndices lignificados, de ápice agudo e que dão aspecto espinhoso ao limbo de $M$. dolens var. anisitsii (Fig. 5h).

O mesofilo é dorsiventral, com uma camada de parênquima paliçádico ocupando cerca de metade da espessura do limbo e o restante 

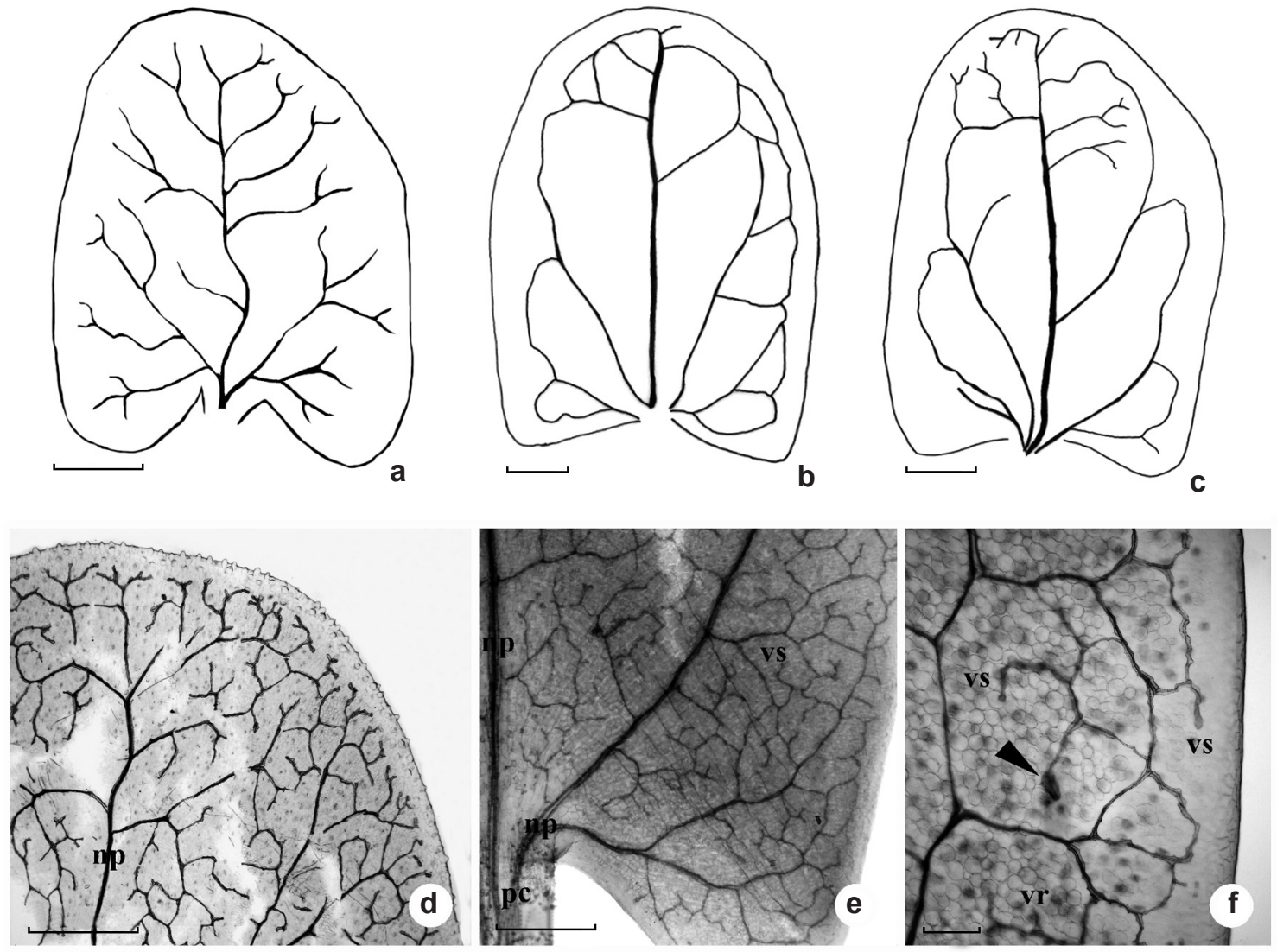

Figura 4 - Venação dos cotilédones de Mimosa daleoides (a, d), Mimosa dolens var. anisitsii (b, f) e Mimosa orthacantha (c, e) - a-c. padrão básico de venação; d-e. detalhe da região apical e basal respectivamente; f. detalhe de aréolas, com vênulas simples e ramificadas (ponta de seta: traqueídes terminais). (np: nervura primária, pc: pecíolo cotiledonar, vs: vênula simples, vr: vênula ramificada). Barras: $1 \mathrm{~mm}$ (a-c), $500 \mu \mathrm{m}$ (d), $150 \mu \mathrm{m}$ (e-f).

Figure 4 - Cotyledon venation of Mimosa daleoides (a, d), Mimosa dolens var. anisitsii (b, f) and Mimosa orthacantha (c, e) - a-c. basic pattern of venation; d-e. detail of the apical and basal region, respectively; f. detail of areole, with simple and branched venules (arrowhead: terminal tracheids). (np: primary vein, pc: cotyledonar petiole, vs: simple venule, vr: branched venule). Bars: $1 \mathrm{~mm}$ (a-c), $500 \mu \mathrm{m}(\mathrm{d}), 150 \mu \mathrm{m}(\mathrm{e}-\mathrm{f})$.

constituído por parênquima lacunoso (Figs. 5c-e). Idioblastos fenólicos encontram-se dispersos no mesofilo de M. daleoides e M. dolens var. anisitsii.

Os feixes vasculares são colaterais, com bainha esclerenquimática no feixe central na base do folíolo apical de M. dolens var. anisitsii (Fig. 5d) e nos feixes de maior calibre de $M$. orthacantha; nos demais, nota-se apenas a endoderme.

A ráquis do eofilo das três espécies é estomatífera, apresentando epiderme glabra e com diferenciação do córtex em uma camada paliçádica em $M$. daleoides e $M$. dolens var. anisitsii, duas em $M$. orthacantha, todas voltadas para a face adaxial. O feixe vascular é central, único e colateral, acompanhado por bainha esclerenquimática (Fig. 5i). Em M. orthacantha nota-se um traço foliolar
(Fig. 5i). A estipela distal é vascularizada por um feixe colateral com fibras e endoderme com alguns cristais em $M$. dolens var. anisitsii; não há diferenciação em parênquima paliçádico; porém, o parênquima é clorofiliano (Fig. $5 \mathrm{j}$ ).

Com relação à vascularização dos eofilos, observa-se que a nervura primária apresenta sua primeira ramificação ainda nos peciólulos dos dois pares de folíolos de M. daleoides (Fig. 6a) e no par de folíolos apical de M. dolens var. anisitsii (Fig. 6b). Em M. orthacantha, notam-se duas nervuras primárias em todos os folíolos, uma levemente mais espessa que a outra (Fig. 6c). Em todas as espécies, as nervuras primárias são retas, alcançam o ápice com traqueídes terminais nítidos em M. dolens var. anisitsii (Fig. 6d) e reduzidos em M. orthacantha (Fig. 6e). 


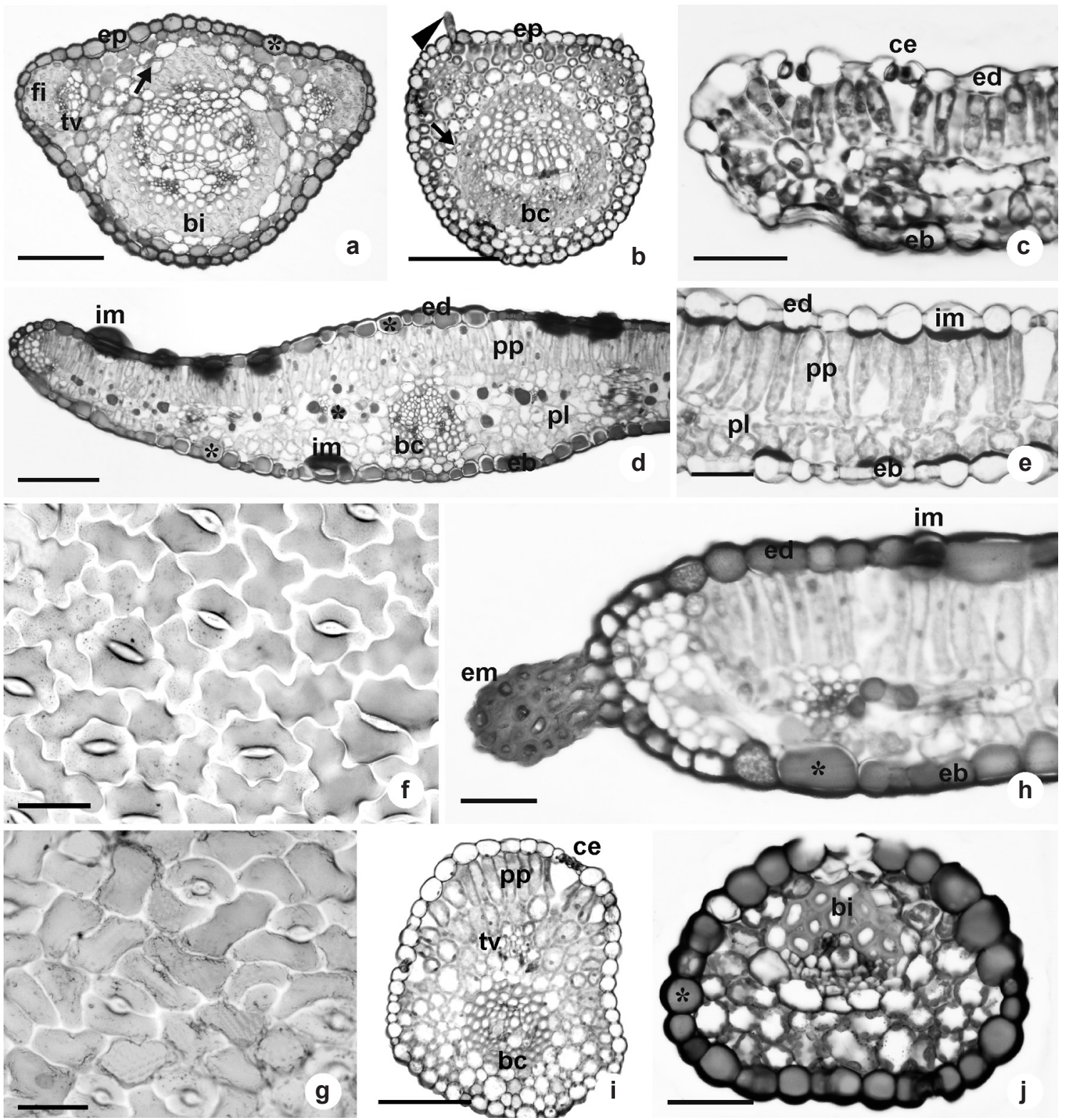

Figura 5 - Anatomia dos eofilos de Mimosa daleoides (c, f), Mimosa dolens var. anisitsii (a, d, h, j) e Mimosa orthacantha Benth. (b, e, g, i). Secções transversais (a-e, h-j), impressões epidérmicas (f-g) - a-b. pecíolos com cristais prismáticos (seta); notar bainha esclerenquimática incompleta na primeira espécie, e tricomas (ponta de seta) e bainha esclerenquimática completa restritos à segunda espécie; c. bordo do folíolo; d. limbo, incluindo região do bordo à nervura central do folíolo; e. detalhe do semilimbo do folíolo; f-g. face abaxial e adaxial respectivamente; h. detalhe do bordo foliolar, com emergência lignificada; i. ráquis; j. estipela distal. (bc: bainha esclerenquimática completa, bi: bainha esclerenquimática incompleta, ce: complexo estomático, eb: epiderme na face abaxial, ed: epiderme na face adaxial, em: emergência, ep: epiderme, fi: fibras, im: idioblasto mucilaginoso, pl: parênquima lacunoso, pp: parênquima paliçádico, tv: traço vascular, *: compostos fenólicos). Barras: $100 \mu \mathrm{m}$ (a-b, h-i), $50 \mu \mathrm{m}$ (c, e-g, j), $150 \mu \mathrm{m}$ (d).

Figure 5 -Eophyll anatomy of Mimosa daleoides (c, f), Mimosa dolens var. anisitsii (a, d, h, j) and Mimosa orthacantha (b, e, g, i). Cross sections (a-e, h-j), epidermal printings (f-g) - a-b. petioles with prismatic crystals (arrow); note incomplete sclerenchymatic sheath in the first species, and trichomes (arrowhead) and complete sclerenchymatic sheath restricted to the second species; c. margin of the leaflet; d. blade, including the margin to the midrib of the leaflet; e. details of the leaflet semiblade; f-g. abaxial and adaxial, respectively; $h$. detail of leaflet margin with lignified emergence; i. rachis; j. distal stipel. (bc: complete sclerenchymatic sheath, bi: incomplete sclerenchymatic sheath, ce: stomatal complex, eb: epidermis in the abaxial side, ed: epidermis in the adaxial side, em: emergence, ep: epidermis, fi: fibers, im: mucilaginous idioblast, pl: spongy parenchyma, pp: palisade parenchyma, tv: vascular trace, *: phenolic compounds). Bars: $100 \mu \mathrm{m}$ (a-b, h-i), $50 \mu \mathrm{m}$ (c, e-g, j), $150 \mu \mathrm{m}$ (d). 

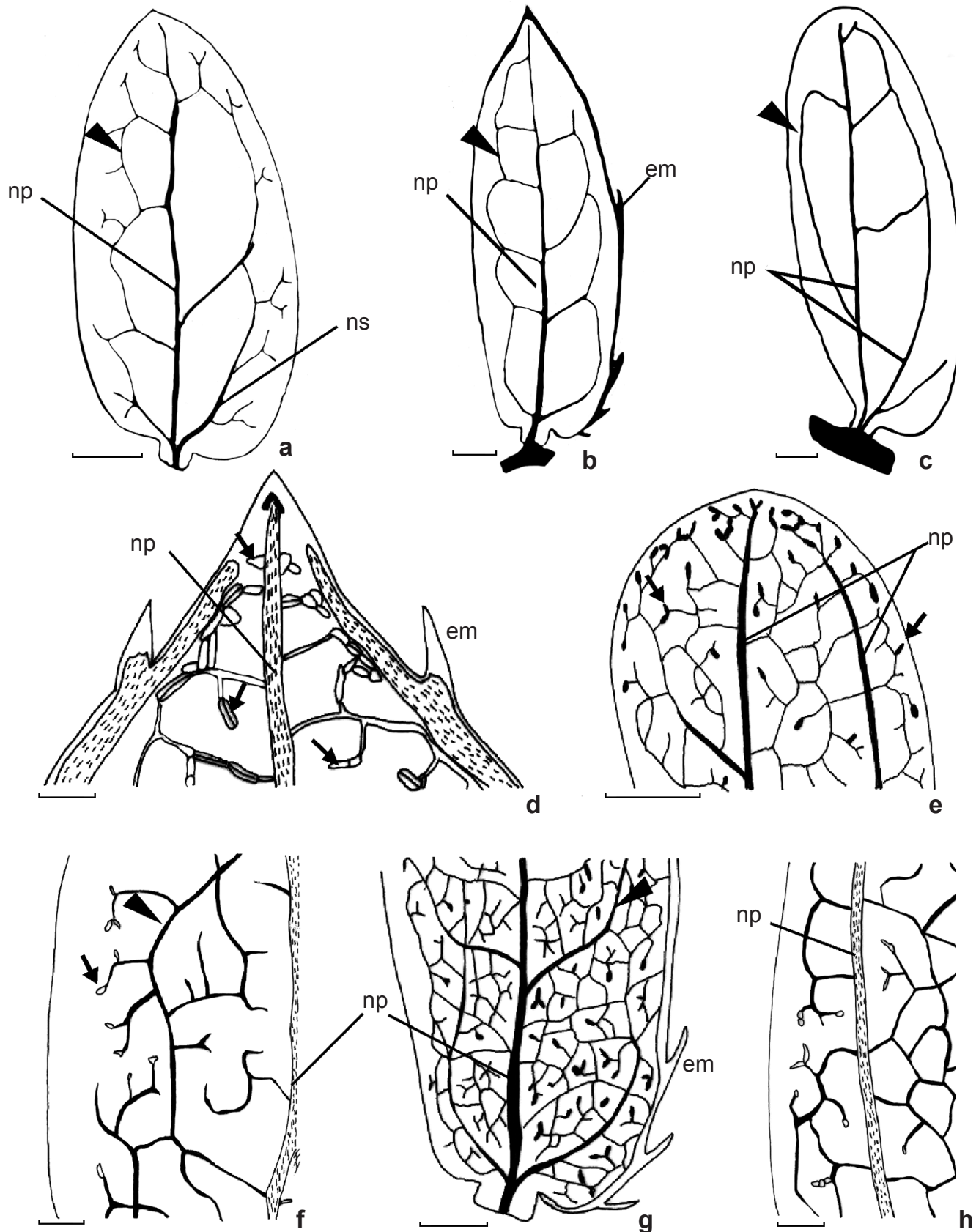

Figura 6 - Venação dos eofilos de Mimosa daleoides (a, f), Mimosa dolens var. anisitsii (b, d, g) e Mimosa orthacantha (c, e, h) - a-b. padrão de venação do par basal de folíolos; c. padrão de venação do folíolo mediano; d. detalhe do ápice do folíolo; notar traqueídes terminais (seta) e apêndices pontiagudos; e. detalhe da Fig. 6c, mostrando ápice obtuso do folíolo (seta: traqueídes terminais); f. bordo de folíolo, evidenciando o arco formado pela nervura secundária (ponta de seta); observar traqueídes terminais distintas (seta); g. base do folíolo; notar aréolas, vênulas e apêndices (ponta de seta: arco formado pela nervura secundária); h. bordo do folíolo próximo a uma das nervuras primárias. (em: emergência, np: nervura primária, ns: nervura secundária). Barras: $500 \mu \mathrm{m}(\mathrm{a}-\mathrm{c}, \mathrm{e}, \mathrm{g}), 50 \mu \mathrm{m}(\mathrm{d}, \mathrm{f}, \mathrm{h})$.

Figure 6 - Eophyll venation of Mimosa daleoides (a, f), Mimosa dolens var. anisitsii (b, d, g) and Mimosa orthacantha (c, e, h) - a-b. venation pattern of the basal pair of leaflets; $c$. venation pattern of median leaflet; $d$. detail of the leaflet apex; note terminal tracheids (arrow) and appendages; e. detail of Fig. 6c, showing obtuse apex of the leaflet (arrow: terminal tracheids); f. margin of the leaflet, showing the arc formed by the secondary veins (arrowhead); observe evident terminal tracheids (arrow); g. base of leaves; note areoles, venules and appendages (arrowhead: arc formed by secondary vein); h. margin of leaflet, near of a primary rib. (em: emergence, np: primary vein, ns: secondary vein). Bars: $500 \mu \mathrm{m}$ (a-c, e, g), $50 \mu \mathrm{m}$ (d, f, h). 
O número de nervuras secundárias varia entre as espécies, com aproximadamente sete no par de folíolos basal e cinco no apical de M. daleoides; nove em $M$. dolens var. anisitsii e são raras em $M$. orthacantha. Nas três espécies, as nervuras secundárias alongam-se e unem-se às adjacentes, formando venação do tipo broquidódroma (Figs. 6a-c, f-g). Em M. orthacantha, esses arcos são evidenciados, porém menos expressivos, além do que, são duas nervuras principais formadas, divergindo das demais (Fig. 6c).

As vênulas partem de todos os níveis de venação e podem ser simples ou ramificadas nas três espécies, com ou sem traqueídes terminais distintas. As aréolas apresentam desenvolvimento incompleto, arranjo aleatório, formato poligonal e são grandes em $M$. daleoides (Fig. 6f); em $M$. dolens var. anisitsii, são bem desenvolvidas, também de arranjo aleatório, formato variado e pequenas (Fig. 6g); em M. orthacantha, as aréolas são esparsas, faltando em algumas regiões, com tamanho e formas bem irregulares (Fig. 6h).

\section{Discussão}

As plântulas estudadas das três espécies de Mimosa enquadram-se no tipo fanero-epígeofoliácea (PEF), segundo a nomenclatura de Garwood (1996), ou seja, são plântulas que expõem seus cotilédones foliáceos acima do solo. Esta classificação alia a morfologia com estratégias ecológicas das plântulas, de modo que o tipo $\mathrm{PEF}$ relaciona-se ao seu rápido estabelecimento, o que pode explicar o comportamento dessas três espécies, principalmente $M$. daleoides e $M$. orthacantha. Mimosa dolens var. anisitsii exibe rápido desenvolvimento, porém não são observadas em populações, como as demais espécies, fato esse que pode estar relacionado com o modo de deiscência dos frutos e a dispersão das sementes (Iwazaki 2008).

Gates (1951) relatou que as espécies de Mimosoideae e Caesalpinioideae sensu lato parecem ser todas epígeas, enquanto que, em Faboideae, as plântulas apresentam tipos variados de germinação. Polhill et al. (1981) confirmaram esses dados complementando que, em Mimosoideae e Caesalpinioideae sensu lato, os cotilédones são foliáceos, podendo também apresentar alguma reserva, normalmente persistindo até a expansão do primeiro eofilo. No presente trabalho, verificamse todas essas características, com os cotilédones permanecendo fotossintetizantes mesmo após a expansão completa do primeiro eofilo.
Embora a capacidade de nodulação por bactérias fixadoras de nitrogênio (Rhizobium) seja característica das leguminosas, comum em Mimosoideae e Faboideae, rara em Caesalpinioideae sensu lato (Corby 1981), nódulos não foram observados nas plântulas das três espécies de Mimosa até a fase estudada (com seis a dez dias). Na planta jovem, cerca de dois a cinco meses após a germinação, a formação de nódulos é observada, indicando que as espécies estudadas são capazes de nodular (observação pessoal).

Todas as espécies de Mimosa estudadas no presente trabalho mostram cotilédones foliáceos com mesofilo dorsiventral, enquadrando-se no tipo 2 proposto por Smith (1981), em que não há distinção entre a nervura central e o restante do limbo; porém, exibem a face adaxial levemente convexa, principalmente em $M$. dolens var. anisitsii e $M$. orthacantha, e a face abaxial convexa. Smith (1981) afirmou que diferenças nos cotilédones são potencialmente importantes para se compreender relações taxonômicas e filogenéticas; relatou, ainda, que, muitas características podem ser usadas na identificação de espécies. O autor distinguiu, para as Fabaceae, quatro tipos de cotilédones pela combinação de caracteres anatômicos e morfológicos, estando os foliáceos em um extremo e os carnosos em outro. Cotilédones foliáceos apresentam mesofilo heterogêneo, em contrapartida aos carnosos, que possuem somente parênquima com reservas. A maioria dos cotilédones carnosos apresenta tempo de vida bem mais curto em relação aos foliáceos, permanecendo por duas ou três semanas e por vários meses respectivamente (Smith 1981).

Comparando-se a sinuosidade das paredes anticlinais da epiderme das três espécies de Mimosa para cotilédones e eofilos, verifica-se que, apesar da sinuosidade ser bem mais evidente nos eofilos, já é observada nos cotilédones, porém em menor intensidade, principalmente em $M$. daleoides. Moreira-Coneglian \& Oliveira (2006), analisando espécies de Caesalpinioideae sensu lato, também constataram esta variação, além de verificarem diferenças entre as faces nos cotilédones de Peltophorum dubium (Spreng.) Taub. Metcalfe (1979) generalizou que a sinuosidade é mais acentuada na face abaxial que na adaxial, enquanto Watson (1942) considerou que o grau de sinuosidade das paredes celulares epidérmicas varia com as condições luminosas, com as folhas mais iluminadas apresentando paredes anticlinais mais 
retas. Por isso, assim como sugerido por Moraes \& Paoli (1999), informações desta natureza não são indicadas para fins taxonômicos.

Ao comparar cotilédones e eofilos das três espécies de Mimosa, verifica-se que o parênquima paliçádico é mais desenvolvido nos eofilos, além de especialização das células epidérmicas, como idioblastos mucilaginosos em maior quantidade e idioblastos fenólicos. Esau (1974) observou que o mesofilo das primeiras folhas apresenta-se menos diferenciado que o das folhas subsequentes.

Estudos anatômicos das primeiras folhas de Mimosoideae são escassos, havendo poucas referências também com folhas adultas. A respeito destas, registram-se os trabalhos de Leelavathi et al. (1980), que estabeleceram uma relação da distribuição dos estômatos com a taxonomia da subfamília; Lersten \& Curtis (1993) analisaram a venação de duas espécies de Calliandra Benth.; Vilela (1993) descreveu as adaptações xeromórficas de folhas de Prosopis nigra Hieron.; e Mendes \& Paviani (1997) compararam duas espécies de Plathymenia Benth., uma de floresta úmida e outra de cerrado, evidenciando que a espécie de ambiente seco apresenta estômatos mais profundos, mesofilo mais denso, com duas camadas de parênquima paliçádico e aumento da espessura da cutícula. Baseada nessa relação estrutura e ambiente, e nas descrições feitas por Esau (1974) e Menezes et al. (2006), verifica-se que folhas xeromórficas também apresentam paredes celulares espessas, principalmente a periclinal externa e maior quantidade de parênquima paliçádico, além de outras características. As espécies de Mimosa em estudo, apesar de presentes em remanescentes de cerrado, não exibem adaptações claras a esse bioma nas primeiras folhas, a não ser pela parede externa da epiderme, que se mostra espessada por substâncias de natureza péctica, porém com cutícula delgada. Como cotilédones e eofilos são folhas transitórias no indivíduo, este dado não se mostra discrepante; a análise dos metafilos, folhas definitivas e típicas das espécies, poderá revelar informações mais relacionadas às adaptações ao bioma.

Para o padrão geral de venação dos cotilédones de Mimosoideae, Smith \& Scott (1995) descreveram que a subfamília apresenta até sete nervuras primárias, normalmente originadas de quatro feixes peciolares. Mimoseae pode apresentar variados padrões de venação, alternando tanto no número de feixes no pecíolo quanto no limbo. As três espécies estudadas de Mimosa enquadram-se no padrão "3.3" proposto pelos referidos autores, com dois feixes vasculares no pecíolo e três nervuras primárias no limbo, o que conduz ao tipo actinódromo (Hickey 1979). Já os eofilos, apresentam venação broquidódroma (Hickey 1979), sendo que se registram duas nervuras primárias com diferentes calibres em $M$. orthacantha e, nas demais, apenas uma nervura primária que se ramifica logo na base, divergindo, então, do padrão broquidódromo proposto por Hickey (1979).

Lucknow (2002), estudando a venação de folhas adultas de Mimosoideae, também descreveu que os padrões encontrados podem variar daqueles propostos por Hickey (1979) e Flores-Cruz et al. (2004), ao estudarem 39 espécies de Mimosa, verificaram que os foliólulos exibem venação broquidódroma, revelando que esse deve ser o padrão para o gênero.

Os cotilédones das espécies estudadas de Mimosa exibem poucas e pequenas traqueídes terminais, mais abundantes nos eofilos, principalmente em $M$. dolens var. anisitsii. Tais traqueídes foram tratadas como idioblastos terminais por Lucknow (2002), caracterizadas por serem células lignificadas, presentes no ápice das nervuras de folhas adultas de Mimosoideae. $\mathrm{Na}$ verdade, tais células são traqueídes com diversas formas e arranjos, alongadas, com parede secundária reticulada ou escalariforme. $\mathrm{O}$ grau de especialização desses "idioblastos" e o número de esclereídes podem aumentar conforme a aridez onde as plantas são encontradas.

As nervuras primárias, dentre as espécies de Mimosa estudadas por Flores-Cruz et al. (2004), podem ser retas ou sinuosas, as aréolas geralmente são bem desenvolvidas, com vênulas simples, lineares ou curvas, ou ramificadas. Considerando as espécies aqui relatadas, as nervuras primárias mostram-se todas retas. As aréolas são mais variáveis, de esparsas a ausentes em algumas regiões de $M$. orthacantha, incompletas em $M$. daleoides e bem desenvolvidas somente em $M$. dolens var. anisitsii.

Por fim, vale destacar que Garwood (1996) relatou que a demanda de manuais de identificação vem crescendo, principalmente para fins de manejo e conservação. É interessante incluir espécies de Mimosa em tais manuais; no entanto, isso deve ser feito com a devida atenção, pois o gênero apresenta tanto espécies invasoras de culturas que, 
consequentemente, precisam ser remanejadas, como M. pigra (Steinbauer et al. 2000; Paynter 2005; Ostermeyer \& Grace 2007), quanto espécies importantes para reflorestamentos, recuperação de áreas degradadas, e com alto grau de endemismo, que necessitam ser preservadas.

Sendo assim, o presente estudo pode auxiliar futuras análises de identificação de espécies de Mimosa, principalmente no que diz respeito ao seu desenvolvimento inicial, uma vez que material para este tipo de consulta é escasso e o conhecimento da estrutura das plântulas, por exemplo, pode auxiliar na identificação precoce, colaborando para a seleção de espécies úteis e/ou favorecendo o controle de invasoras.

\section{Agradecimentos}

Ao CNPq, pela bolsa de mestrado de Maísa de Carvalho Iwazaki e pela bolsa de produtividade em pesquisa de Denise Maria Trombert Oliveira (processo no 309416/2011-6). A Valquíria Ferreira Dutra, pela identificação das espécies.

\section{Referências}

Camargo-Ricalde, S.L. \& Grether, R. 1998. Germinación, dispersión y establecimiento de plántulas de Mimosa tenuiflora (Leguminosae) en Mexico. Revista de Biología Tropical 46: 543-554.

Corby, H.D.L. 1981. The systematic value of leguminous root nodules. In: Polhill, R.M. \& Raven, P.H. (eds.). Advances in legume systematics. Royal Botanic Garden, Kew. Pp. 657-669.

Duke, J.A. \& Polhill, R.M. 1981. Seedlings of Leguminosae. In: Polhill, R.M. \& Raven, P.H. (eds.). Advances in legume systematics. Royal Botanic Garden, Kew. Pp. 941-949.

Esau, K. 1974. Anatomia das plantas com sementes. Ed. Edgard Blücher, São Paulo. 293p.

Ferreira, A.G. \& Borghetti, F. 2004. Germinação. Do básico ao aplicado. Porto Alegre, Editora Artmed. 323p.

Flores-Cruz, M.; Santana-Lira, H.D.; Koch, S.D. \& Grether, R. 2004. Taxonomic significance of leaflet anatomy in Mimosa series Quadrivalves (Leguminosae, Mimosoideae). Systematic Botany 29: 892-902.

Fuchs, C.H. 1963. Fuchsin staining with $\mathrm{NaOH}$ clearing for lignified elements of whole plants or plants organs. Stain Technology 38: 141-144.

Garwood, N.C. 1996. Functional morphology of tropical tree seedlings. In: Swaine, M.D. (ed.). The ecology of tropical forest tree seedlings. The Parthenon Publishing Group, New York. Pp. 59-129.

Gates, R.R. 1951. Epigeal germination in the Leguminosae. Botanical Gazette 113: 151-157.
Hickey, L.J. 1979. A revised classification of the architecture of dicotyledonous leaves. In: Metcalfe, C.R. \& Chalk, L. (eds.). Anatomy of the dicotyledons. Vol. 1. Clarendon Press, Oxford. Pp. 25-39.

Iwazaki, M.C. 2008. Frutos, sementes e plântulas de três espécies de Mimosa Linnaeus (Fabaceae: Mimosoideae): aspectos morfoanatômicos e considerações ecológico-filogenéticas. Dissertação de mestrado. Universidade Estadual Paulista (UNESP), Botucatu. 108p.

Jensen, W.A. 1962. Botanical histochemistry; principles and practice. San Francisco, W.H. Freeman. 408p.

Johansen, D.A. 1940. Plant microtechnique. McGrawHill, New York. 523p.

Judd, W.S.; Campbell, C.S.; Kellog, E.A. \& Stevens, P.F. 2009. Sistemática vegetal: um enfoque filogenético. Artmed, São Paulo. 612p.

Kraus, J.E. \& Arduin, M. 1997. Manual básico de métodos em morfologia vegetal. EDUR, Seropédica. 198p.

Lersten, N.R. \& Curtis, J.D. 1993. Paraveinal mesophyll in Calliandra tweedii and C. emarginata (Leguminosae: Mimosoideae). American Journal of Botany 80: 561-568.

Leelevathi, P.; Ramayya, N. \& Prabhakar, M. 1980. Foliar stomatal distribution patterns in Leguminosae and their taxonomic significance. Phytomorphology 30: 195-204.

Lucknow, M. 2002. Anatomical features of the leaves in the Dichrostachys group (Leguminosae: Mimosoideae) and their utility for phylogenetic studies. Systematic Botany 27: 29-40.

Mendes, I.D.A. \& Paviani, T.I. 1997. Morfo-anatomia comparada das folhas do par vicariante Plathymenia foliosa Benth. e Plathymenia reticulata Benth. (Leguminosae-Mimosoideae). Revista Brasileira de Botânica 20: 185-195.

Menezes, N.L.; Silva, D.C. \& Pinna, G.F.A.M. 2006. Folha. In: Appezzato-da-Glória, B. \& CarmelloGuerreiro, S.M. (eds.). Anatomia vegetal. $2^{\text {a }}$ ed. Editora UFV, Viçosa. Pp. 303-325.

Metcalfe, C.R. 1979. The leaf: general topography and ontogeny of the tissues. In: Metcalfe, C.R. \& Chalk, L. (eds.). Anatomy of the dicotyledons. Vol. 1. Clarendon Press, Oxford. Pp. 97-165.

Moraes, P.L.R. \& Paoli, A.A.S. 1999. Epiderme e padrão de venação foliar de espécies de Lauraceae. Acta Botanica Brasilica 13: 87-97.

Moreira-Coneglian, I.R. \& Oliveira, D.M.T. 2006. Anatomia comparada dos limbos cotiledonares e eofilares de dez espécies de Caesalpinioideae (Fabaceae). Revista Brasileira de Botânica 29: 193-207.

O’Brien, T.P.; Feder, N. \& McCully, M.E. 1964. Polychromatic staining of plant cell walls by toluidine blue O. Protoplasma 59: 368-373. 
Oliveira, D.M.T. 1999. Morfologia de plântulas e plantas jovens de 30 espécies arbóreas de Leguminosae. Acta Botanica Brasilica 13: 263-269.

Oliveira, D.M.T. 2001. Morfologia comparada de plântulas e plantas jovens de leguminosas arbóreas nativas: espécies de Phaseoleae, Sophoreae, Swartzieae e Tephrosieae. Revista Brasileira de Botânica 24: 85-97.

Ostermeyer, N. \& Grace, B.S. 2007. Establishment, distribution and abundance of Mimosa pigra biological control agents in northern Australia: implications for biological control. Biocontrol 52: 703-720.

Paynter, Q. 2005. Evaluating the impact of a biological control agent Carmenta mimosa on the woody wetland weed Mimosa pigra in Australia. Journal of Applied Ecology 42: 1054-1062.

Parra, P. 1984. Estudio de la morfología externa de plántulas de Calliandra gracilis, Mimosa albida, Mimosa arenosa, Mimosa camporum y Mimosa tenuiflora. Revista de la Facultad de Agronomia 13: 311-350.

Polhill, R.M.; Raven, P.H. \& Stirton, C.H. 1981. Evolution and systematics of the Leguminosae. In: Polhill, R.M. \& Raven, P.H. (eds.). Advances in legume systematics. Royal Botanic Gardens, Kew. Pp. 1-26.

Ressel, K.; Guilherme, F.A.G.; Schiavini, I. \& Oliveira, P.E. 2004. Ecologia morfofuncional de plântulas de espécies arbóreas da Estação Ecológica do Panga, Uberlândia, Minas Gerais. Revista Brasileira de Botânica 27: 311-323.

Ricardi, M. 1996. Morfología de los cotiledones de plántulas de algunas familias o géneros presentes en Venezuela como fuente de caracteres para su determinación. Plantula 1: 1-11.

Saint-Martin, M. 1984. Ontogénie des plantules et phytodermologie chez les Papilionaceae. Gaussenia 1: 19-44.

Scott, R.C. \& Smith, D.L. 1998. Cotyledon architecture and anatomy in the Acacieae (Leguminosae: Mimosoideae). Botanical Journal of the Linnean Society $128:$ 15-44.

Smith, D.L. 1981. Cotyledons of the Leguminosae. In: Polhill, R.M. \& Raven, P.H. (eds.). Advances in legume systematics. Royal Botanic Garden, Kew. Pp. 927-940.

Smith, D.L. 1983. Cotyledon anatomy in the Leguminosae. Botanical Journal of the Linnean Society $86:$ 325-355.

Smith, D.L. \& Scott, R.C. 1985. Cotyledon venation patterns in the Leguminosae: Caesalpinioideae. Botanical Journal of the Linnean Society 90: 73-103.

Smith, D.L. \& Scott, R.C. 1995. Cotyledon venation patterns in the Leguminosae: Mimosoideae. Botanical Journal of the Linnean Society 119: 213-243.

Steinbauer, M.J.; Edwards, P.B.; Hoskins, M.; Schatz, T. \& Forno, I.W. 2000. Seasonal abundance of insect biocontrol agents of Mimosa pigra in the Northern Territory. Australian Journal of Entomology 39: 328-335.

Vilela, A.E. 1993. Anatomia foliar de Prosopis (Leguminosae-Mimosoideae): estratégias adaptativas a diferentes ambientes en Prosopis nigra. Darwiniana 32: 99-107.

Watson, R.W. 1942. The effect of cuticular hardening on the epidermal cells. New Phytologist 41: 223-229. 